\title{
INTERRUPCIONES MOMENTÁNEAS DE LA CONVENCIÓN \\ APORTES PARA LA COMPRENSIÓN DE IRREDENTOS De Antonio ACEvedo Hernández
}

\author{
Mauricio Barría Jara \\ Departamento de Teatro \\ Universidad de Chile \\ mbarriajara@hotmail.com
}

RESUMEN / ABSTRACT

El artículo propone una lectura de la obra Irredentos de Antonio Acevedo Hernández, intentando mostrar las innovaciones dramatúrgicas que contiene en el contexto del teatro chileno de la época. Para ello se recurre a la aplicación de un marco de análisis que vincula la obra acevediana con tópicos de las vanguardias artísticas teatrales de inicios del siglo XX, especialmente sus vínculos con la categoría de teatro político propuesta por Erwin Piscator y el concepto de estructura de sentimiento propuesto por Raymond Williams.

Palabras Clave: Acevedo Hernández, teatro político, drama social y vanguardia teatral.

The article proposes a reading of the dramaturgical innovations of the play Irredentos by Antonio Acevedo Hernández in the context of the Chilean theater at the beginning of the $20^{\text {th }}$ century. An analytical framework that links Acevedo's work with topics of theatrical avantgarde of the period is applied. Emphasislies on the relationship between his work with the category of Political Theater by Erwin Piscator, and the concept of structure of feeling by Raymond Williams.

KEY WORDS: Acevedo Hernández, political theater, social drama, theatrical avant-garde. 
La obra de Antonio Acevedo Hernández nos plantea un gran desafío, pues detrás de su aparente convencionalidad encontramos a un autor con una plena conciencia que, como pocos en ese tiempo, reflexionó sobre su quehacer y entendió que detrás de una decisión formal existe una política determinada del arte. En "Consideraciones sobre el teatro chileno" de 1933, Acevedo desarrolla una extensa crítica al panorama escénico chileno de la época acusando a algunos de sus contemporáneos de una falta de compromiso respecto a la posteridad, puesto que muchos escriben pensando más en la fama inmediata o en el reembolso de la taquilla; ante ello insta a la necesidad de estar atentos a los cambios del presente. La claridad con la que expone por qué el arte pictórico debe convertirse en un modelo para la creación es una prueba de esta conciencia propia del espíritu de la vanguardia, por ejemplo, cuando afirma que la plástica no ha descubierto una nueva estética, sino más bien "aprendió sencillamente a mirar y a realizar de una nueva manera y a producir emoción con procedimientos más dinámicos, de acuerdo con el tiempo que es algo vertiginoso, algo que nuestros abuelos no pudieron soñar" (Acevedo 1933: 313). O cuando de forma premonitoria afirma el fracaso del teatro ante el poder de representación del cine, por lo que debe buscar nuevas formas de representar y entonces cita nada más y nada menos que a Piscator: "para los que combaten el realismo en el teatro" (314).

Esta lucidez histórica sobre los procesos artísticos, que Acevedo echa tanto de menos en sus contemporáneos, es lo que diferenciará su obra, independiente de sus logros concretos, de la de muchos de éstos. Y digo lo anterior, pues esta radical historicidad lo que primero pondrá en crisis será la idea misma de "convencionalidad”.

\section{ENTRE CONVENCIONALIDAD E INNOVACIÓN}

La ambigüedad que contiene la idea de lo "convencional” es apuntada por Raymond Williams (1975) para referirse al problema que las nuevas escrituras dramáticas de las vanguardias y de las posvanguardias le plantean al crítico literario cuando intenta apreciar el alcance de sus innovaciones. Lo convencional implica tanto un acuerdo tácito consensuado, como la idea de normas o reglas aceptadas por la tradición y en ese sentido, impuestas de algún modo. La primera acepción refiere a la libertad de lo que no es ni permanente ni necesario, la segunda representa el límite conservador de lo reificado. Sin embargo, en uno u otro caso, hay implicado algún tipo de 
acuerdo y aceptación entre las partes involucradas en la relación. En el caso del teatro, esto adquiere una especial relevancia, pues de algún modo toda puesta en escena no es sino la escenificación amplificada de una convención: desde la manera en que se concibe la realidad en un montaje naturalista, a la verosimilitud que tiene el soliloquio de un personaje, o la forma de trabajar el tiempo en el teatro en el que cinco minutos escénicos pueden representar la larga espera de un condenado. De alguna manera, todo lo que propone un autor teatral es una convención atada entre lo contingente y lo necesario, vale decir, entre la nueva convención que propone ese autor en esa obra, y la necesaria confirmación social, el acuerdo tácito de convertir esa innovación en convención y trabajar desde aquellas recibidas por la tradición: “Tenemos por tanto necesidad de la tradición -convención como acuerdo tácito- e igual necesidad al mismo tiempo de experimentación, del desarrollo de formas nuevas de sentimiento, de la percepción de medios técnicos nuevos o redescubiertos -convención como método dramático" (17).

Lo notable acá es que Williams no entiende esta idea como una simple abstracción cultural, sino como una técnica de producción artística que consiste en un efecto determinado sobre un público determinado, por consiguiente, el rol capital que tiene ese espectador para confirmar el poder de la convención, su capacidad de llegar a ser tal, es lo que definiría al arte en general y al teatro muy en particular. Williams no lo remite a la típica imagen de la incomprensión de un público ante la novedad, más bien para Williams el teatro se mide inmediatamente y cada vez con ese acuerdo aceptado en que consiste el juego de la convención .

Extrapolando el argumento de Raymond Williams, con Acevedo pasaría lo que con algunos autores dramáticos, cuyas obras no son portadoras de grandes innovaciones, que más bien han realizado pequeños desplazamientos o variaciones de la norma frente a otras que denotan en su estructura más evidente tales transformaciones. Un ejemplo de ello sería Von Kleist (1973), en contraposición a Büchner (1960). Una texto como Pentesilea, en apariencia de estructura clásica, esconde ciertos recursos que cuestionan el canon del drama absoluto, independientemente de su tema o de que vulnere las unidades composición de tiempo y espacio, esa especie de "casualidad" que mueve la acción, esos personajes que no son agentes, sino más bien son movidos, como marionetas por lo excesivo de las situaciones, introducen un malestar al interior del canon en términos de su capacidad omnipotente de representar el mundo, vale decir, de ser convención. Este desvío sutil, del que puedo o no hacerme cargo, contrasta, por su mayor evidencia con la utilización de 
recursos épicos en un texto como La muerte de Dantón de Büchner (1960), en el que la fragmentación del relato lineal o la fractura de las formas del diálogo interpersonal del drama clásico son palpables. Estas obras que realizan pequeños desplazamientos tienen un efecto corrosivo en el tiempo, a la larga provocan un pequeño malestar, algo que podría ser imaginado como una interrupción momentánea de la convención.

La crítica hermenéutica que alude siempre al horizonte de una tradición tiende a fijarse más en las grandes transformaciones que en los pequeños corrimientos que un autor determinado genera sobre esa tradición. Esos pequeños desajustes muy a menudo son señalados como excepciones de una regla que vendrían de una forma u otra a ratificar la fuerza de ley del canon en cuestión. Asimismo, la valoración de una obra quedará entonces sujeta a la dinámica de una oposición algo viciosa entre innovación y conservación, perdiéndose así el potencial crítico que pudo haber tenido en un momento determinado, atribuyéndosele a esos pequeños descalces la condición de meros errores o de desprolijidades constructivas. De lo que aquí se trata es ver de qué manera nos enfrentamos a un material artístico determinado, cuánta atención prestamos o no a los pequeños detalles y encontramos en ellos una real posibilidad hermenéutica. Es en esta misma línea que Walter Benjamin (1998) denuncia la obsolescencia de la oposición entre forma y contenido que define la crítica formalista, como de la oposición entre tendencia y calidad que es el equivalente ideológico de una crítica de izquierda que, de algún modo, arrancan la obra de su auténtica historicidad. Para salvar estas falsas dicotomías propone la categoría de técnica. A través de ella comprende la realización de una obra preferentemente como un proceso, el que está íntimamente ligado a los modos como suceden las relaciones de producción de una época, es decir, a ese devenir concreto y material en el que una sociedad en particular en un tiempo determinado ha tenido o ha elegido producir su existencia. Esta perspectiva materialista de la creación, como él la denomina, sería para Benjamin el auténtico horizonte histórico desde donde sería posible la comprensión de una obra y, por ende, desde donde sería posible evaluar su novedad relativa, contrariamente al vínculo de perennidad que imagina Gadamer bajo la idea de tradición ${ }^{1}$. La técnica artística, en efecto, no aludiría ni a la idea de un estilo, es decir, a una convergencia entre forma y contenido, ni al modo en que calza una obra con un determinado deber ser 
de la historia y la política, sino a las condiciones finitas en la que tiene lugar concretamente ese proceso de producción de la misma.

Técnica y tradición, aunque en cierto modo opuestas, no son categorías irreconciliables, pero se encontrarían tensionadas cada vez en una obra determinada. La idea de convención propuesta por Williams resulta ser así una herramienta acertada para hacerse cargo de esta tensión, toda vez que cabría entenderla no solo como una red imaginarios mentales que porta el espectador previamente, producto de los aprendizajes culturales en los que ha sido socializado, sino que consideraría también los procesos de recepción de ese público. Entendida así, la convención sería desde el punto de vista de la producción artística una dimensión de la técnica. La interrogante que derivaría de este análisis sería entonces ¿de qué manera surge la obra de Acevedo en función de determinadas condiciones de producción?, es decir, cómo su obra es una respuesta y más, una resistencia a los modos tradicionales de producción teatral, y es ahí donde cobra plena significación ese guiño a la vanguardia que citábamos al inicio y la crítica a sus contemporáneos por falta, precisamente, de contemporaneidad, es decir, incapacidad de leer el presente desde una perspectiva material, y contentarse con la reproducción de estilos o deberes ser político-ideológicos. Acevedo es tremendamente coherente con esa contemporaneidad, él logra convertir su origen (y determinismo) social en una condición afirmativa; su falta de estudios formales en una opción por la autoeducación. Este giro nos permitiría ver la dramaturgia de Acevedo ya no como el reflejo ilustrativo de una casta, cuyo imaginario estaría relegado a una inexorable marginalidad, a una impotencia estructural; por el contrario, lo que jugaría acá sería la invención de una nueva subjetividad, una nueva clase de artista que asume la radicalidad de su condición contemporánea, en tanto comprende su existencia como tensionada materialmente por esta dimensión productiva y la obra como un mecanismo crítico de esa misma realidad ${ }^{2}$.

Por el contrario, la obra de Acevedo (y en general la dramaturgia chilena de los primeros treinta años del siglo XX) sufrió de un fatal confinamiento a los

\footnotetext{
Sobre el sentido de lo que entiendo por “contemporáneo” aquí, permítaseme proponer la siguiente cita de Agamben (2009), que podría aludir perfectamente al caso de Acevedo: "Esto significa que el contemporáneo no es sólo quien, percibiendo la sombra del presente, aprehende su luz invendible; es también quien, dividiendo e interpolando el tiempo, está en condiciones de transformarlo y ponerlo en relación con los otros tiempos, leer en él de manera inédita la historia, “citarla” según una necesidad que no proviene en absoluto de su arbitrio, sino de una exigencia a la que él no puede dejar de responder”.
} 
márgenes. El discurso académico más o menos formalista tendió a acomodar estas dramaturgias en función de los grandes relatos teórico-literarios, sin reparar en las pequeñas modificaciones que podían estar generando sobre o contra ese gran relato hegemónico. Fue así que categorías estilísticas como naturalismo, costumbrismo o melodrama social se atribuyeron al conjunto de estas dramaturgias, no sin razón en la mayoría de los casos, pero que en otros, y específicamente en el de Acevedo, dejaron en suspenso logros potenciales que contenían algunas de sus obras. Pero lo que ha quedado en deuda, es decir, a lo que refiero con estos logros potenciales, es puntualmente al análisis de la dimensión estética de las formas dramáticas, pues si en algo coincide la mayor parte de los estudiosos de la obra de Acevedo es en señalar que logró representar escénicamente los imaginarios de una clase social que hasta ese momento no había sido tratada como correspondía ${ }^{3}$. El problema de nuestra investigación histórica no se encuentra, por lo tanto, en el nivel del análisis temático, sino en el hecho de no apreciar que esos complejos temáticos dialogaron y entraron en crisis con el ensayo de otros recursos de construcción dramática, en otras palabras, se tensionaron con la técnica dramática que Acevedo ensayó en sus obras ${ }^{4}$.

3 Al respecto, Orlando Rodríguez (1964) afirma que tanto Recabarren como Acevedo son los iniciadores de los temas sociales en nuestro teatro, pues "pusieron de manifiesto en los contenidos dramáticos, la contradicciones socio-económicas existentes en el país" (7). En la misma dirección, Julio Durán (1959) plantea que: “Así como Eduardo Barrios inició el teatro de la burguesía media, Acevedo Hernández inauguraba el teatro popular y social” (59). Por su parte Pradenas (2006) lo llama "padre del teatro popular" (262).

$4 \quad$ Coherente con este mismo intento, sería posible aplicar a la dramaturgia de Acevedo algo semejante a lo que Deleuze y Guattari proponen para Kafka (Kafka, por una literatura menor, 1978); en este caso hablaríamos de una "dramaturgia menor". El concepto refiere a la condición de un escritor que, perteneciendo a un grupo marginal, escribe desde una lengua dominante. Uno de los efectos de esta condición de "menoridad" es la desterritorialización de la lengua dominante. En el caso de Acevedo, a diferencia de los ejemplos habitualmente desarrollados que ponen el acento en la distinción cultural, esta situación se verificaría como diferencia de clase. Sobre este punto se puede encontrar un desarrollo más pormenorizado en mi artículo próximo a ser publicado: “Alegoría y menoridad. Dos estrategias filosóficas para la interpretación de textos dramatúrgicos contemporáneos” (Barría, Gestos 60 (en prensa)). 


\section{INTERRUPCIONES TRANSITORIAS DE LA NORMA}

Una categoría que bien podría aplicarse en este caso, y siguiendo a Williams, es lo que él llamará "estructura de sentimiento". Para el crítico inglés, la contradicción que presenta la obra de arte en cuanto es, por una parte, irreductible y singular, y por otra, que apela a elementos culturales de la comunidad destinataria, obliga a detenerse al mismo tiempo en el nivel más singular de la experiencia de una convención, aquella que de partida solo es tal para quien la propone, pero que luego va develando su propia filiación a otras convenciones históricas: "El dramaturgo individual ha hecho esto, mas lo que ha hecho es parte de lo que conocemos sobre un período o estilo general" (18). La estructura de sentimiento intenta comprender la continuidad contradictoria que existiría en la experiencia entre lo particular de un autor, las formas particulares en una obra y el reconocimiento de lo general en tal obra, de los elementos de las formas generales, incluso asumiendo que existen partes de esa obra que no pueden someterse a medida externa alguna.

Desde esta perspectiva, que no alcanza a configura una metodología, desearía comentar algunos aspectos de la dramaturgia de Acevedo que me parecen singulares y que corresponderían a pequeños desajustes de los modelos canónicos, que hablan más de estructuras de sentimiento que de elementos de una poética acabada. A estos desajuste propondré denominarlos interrupciones transitorias/momentáneas de la convención. Partiré proponiendo un cuadro contextual muy general para finalmente detenerme en un texto en particular: Irredentos de 1918.

\section{a) Del Naturalismo al drama social}

Si tuviéramos que decir a qué estilo o tendencia la dramaturgia de Acevedo se adscribe de forma inmediata, sin duda vendrían a nuestra mente la idea de teatro naturalista y de drama social.

El naturalismo es un movimiento principalmente literario que nace como réplica a los excesos subjetivistas y fantasiosos del romanticismo tardío en Francia. El naturalismo pretendió llevar a sus máximas consecuencias el principio especular del drama burgués intentando reproducir la realidad social con una objetividad documental en todos sus aspectos, tanto en los más elevados como los más vulgares. Ideológicamente inspirado en el positivismo comteano, para quien la realidad del mundo es reducible a los datos que nos proporcionan los sentidos como hechos, lo mismo que las leyes que ordenan 
la naturaleza son hechos concatenados por principios de causalidad y utilidad fáctica, los naturalistas se adscribieron también al determinismo biológico del darwinismo. Objetivismo y determinismo fueron los supuestos desde los cuales se levantó una estética que pretendió representar los problemas y anhelos de una emergente clase popular o proletaria. Sin embargo, esta pretensión revolucionaria en términos estilísticos e ideológicos, según señala Szondi (1994), adoptó en términos dramatúrgicos una orientación conservadora (44). La explicación de Szondi es compleja y concluyente. Mientras el tránsito de la nobleza a la burguesía en el drama del siglo XVIII fue coherente con el proceso histórico, la inserción del proletariado en el drama naturalista más bien persiguió sortear esta otra historicidad: "La distancia social sin la cual hubiese sido impensable el drama del Naturalismo acabó acarreándole funestas consecuencias dramatúrgicas" (90). La distancia que supondrá el objetivismo socio-biológico del positivismo termina por exaltar o enfatizar la presencia del pensamiento del autor sobre la realidad social que quería mostrar, generando así un punto de vista hegemónico y absoluto. El drama naturalista que escapa de la historia termina por no ser un reflejo ni de la burguesía de fin de siglo ni de la clase que le surte de personajes, "sino de los unos contemplando a los otros: el autor burgués y la burguesía como público de campesinos y proletariados" (91).

Este sería el fundamento no solo temático, sino estético del naturalismo, que es posible apreciar en un sinnúmero de dramas de corte social que se estrenan y escriben en Chile en las primeras décadas del siglo XX. En el caso de Acevedo, toda su serie de "dramas de conventillo" presentan estas características, especialmente Carcoma de 1916, En el caso de Armando Moock hallamos, tal vez, su modelo más acabado en Los perros, obra estrenada el mismo año de Irredentos ${ }^{5}$. Esta última obra nos permitirá por vía de comparación descubrir los descalces que singularizan la obra de Acevedo, más adelante.

La superación del naturalismo, de acuerdo con el argumento de Szondi, vendrá de la mano del dramaturgo alemán Gerhart Hauptmann quien sería el fundador de lo que Szondi define como drama social:

El dramaturgo social aspira a exponer en términos dramáticos las circunstancias político-económicas a cuyo dictado ha quedado sometida 
la vida de los individuos. Para ello tiene que poner de manifiesto un conjunto de factores que trascienden tanto la situación como la acción individuales, pero que no por ello dejan de determinarlas. Representarlos dramáticamente supone la tarea preliminar de traducir la alienación en términos de actualidad interpersonal (66).

Para develar estos factores que generan el determinismo social, no con el fin necesariamente de su trasformación, que sería uno de los puntos que diferencia el drama social del teatro político ${ }^{6}$, Hauptmann habría introducido, en palabras de Szondi, la figura de un relator épico. En el caso de la emblemática obra Los Tejedores (1892), este relator épico vendría a ser una suerte de tono que adquieren los personajes quienes modifican la forma del diálogo propio del drama moderno, el que varía hacia una forma expositiva ya no interpersonal, asemejándose más a intercambios de ideas y posiciones que buscan presentar estas condiciones de alienación. Los personajes así ya no quedan definidos desde su situación subjetiva, más bien son como roles o funciones sociales productivas; es notorio aquello en la manera de presentarse éstos como tejedores tal o cual, el carpintero Wiegand, el herrero Witting, el hostelero Welzel, el trapero Hörning, etc., anticipándose en alguna medida a la idea del gestus social brechtiano. Con ello, Hauptmann rompe con el precepto de la fábula como un sistema inmanente y autoexplicativo, que es lo que Szondi denomina drama absoluto. No siendo un personaje en particular, sino un "tono" épico transversal, eso permite que cada personaje explicite datos con los que se hace comprensible (aunque igualmente turbadora) la violencia que la obra presenta, pero que el autor parece solo querer mostrar con la misma distancia. También, hace perceptible aquello que en el naturalismo aparecía como puro determinismo, a saber, que la realidad es producto de decisiones económico políticas que toman los individuos bajo intereses de clase: esto es especialmente notorio en las explicaciones acerca de la diferencias de clase que da el fabricante Dreissiger al inicio del acto IV.

Un buen ejemplo donde podemos encontrar algo similar en la dramaturgia de Acevedo Hernández es en La canción rota (1921). Para la investigadora María de la Luz Hurtado (1997), esta obra da un giro de la visión meramente costumbrista desde la cual se habían tratado los problemas rurales hasta ese momento, y que al ser tributaria de un pensamiento socialista revolucionario 
aspira a ser "un drama de educación política, que justifica la lucha social en todas sus formas" (167). Pero La canción rota no es una simple denuncia de los abusos de los patrones y de la complicidad de la policía, visión que es habitual en la llamada dramaturgia social y encuentra su modelo ejemplar en Los tejedores, es también un drama político, como el mismo Acevedo asegura, en el que no solo se representa la explotación, existe la intención de explicarla, de exponer las condiciones que generan esa situación y es eso lo que lo acerca al drama hauptmanniano, que probablemente Acevedo ya conocía en esa época ${ }^{7}$.

En esta misma dirección, un descalce interesante lo constituye, en esta obra, el personaje anómalo de Salvador. La lectura clásica lo presenta como la metáfora del redentor, o el héroe romántico dispuesto al mayor sacrificio por su pueblo. Pero ni discursivamente, ni su actuar nos permiten afirmar con completa seguridad este carácter heroico. Las complejas reflexiones de Salvador, a menudo incomprensibles para sus cercanos, su función de conciencia de los acontecimientos y el hecho de que no es él quien provoca la revuelta final, es decir, no es él quien toma propiamente la decisión del enfrentamiento directo con el patrón, son indicios de lo anterior. Entonces, ¿cuál es la función dramática de Salvador? ¿Hasta qué punto es el protagonista dramático de la intriga y no más bien un instigador indirecto, un catalizador conceptual de las decisiones que tomará, por ejemplo, Jecho? ¿Quién es el que mueve la acción propiamente tal? A mi juicio, Salvador funciona como un dispositivo que viene a poner en crisis el fondo naturalista-costumbrista que propone la fábula de La canción rota. La presencia discursiva de Salvador

\footnotetext{
Es importante consignar que la denominación de “Teatro Político” con que el propio Acevedo denominó su obra y a otras tres más: Irredentos (1918), El gigante ciego (1932), Los caminos de dios (1937), (Durán 1959: 62) y que consta en la página de título de la primera edición de la Canción de 1933, coincide con la denominación de Piscator. Recordemos que Piscator publica Das Politische Theater (El Teatro Político) en 1929 y es traducida en España prontamente en 1930. Acevedo en su ensayo "Consideraciones sobre el teatro chileno", de 1933, lo cita con propiedad. Es posible sostener que en los textos posteriores a esa fecha y en los que consigna el apelativo "teatro político", Acevedo desea se lean en vinculación con las ideas piscatorianas, y que a posteriori denominó así a las obras anteriores. Por otro lado, el drama de Hauptmann fue estrenado en 1892 y publicado el año siguiente. Fue adaptado a iniciativa de José Echegaray por José Francos Rodríguez y Félix González Llana y estrenado en 1894 con el título de El pan del pobre (Fernández Insuela 19) Por lo que es muy probable que ya a comienzos del siglo XX la obra de Hauptmann haya sido conocida por los dramaturgos de corte social en Latinoamérica.
} 
contrasta con las descripciones de vida rural, aparentemente felices, en las que transcurre la anécdota, de modo que aparece como una figura fuera de campo, fuera de convención. Desnuda lo meramente convencional de este fondo. Desde cierto punto de vista, Salvador tendría este tono de relator épico que caracteriza la obra de Hauptmann, más aún, coincidiría con la función de incitador que en Los tejedores es cumplida por Moritz Jager, pues: “[...] precisamente, por su condición de Desconocido que aún no se ha plegado a las circunstancias reinantes, será quien esté capacitado para desencadenar el fuego del alzamiento" (Szondi 74). Un sujeto que aunque perteneciente a la misma clase es al mismo tiempo un desconocido, un sujeto otro que llega no con afanes redentoristas, sino más bien a exponer las razones de la condición de explotación que se esconden debajo de las descripciones de costumbre de ese grupo de campesinos chilenos (por ejemplo, detrás de una carrera de caballos). En este sentido, no es que La canción rota sea stricto sensu una obra de teatro político o un drama de vanguardia, más bien pone en crisis la convención naturalista y melodramática evidenciando las contradicciones políticas que se juegan tanto a nivel temático como formal. El personaje de Salvador tensiona el formato, sin disolverlo por completo, produce una interrupción del mismo, agotándolo como posibilidad discursiva.

En Almas perdidas (1915), por citar otro ejemplo, el descalce respeto del naturalismo es precisamente su crítica al determinismo. Si examinamos la estructura de la obra nos podemos percatar de que uno de los ejes conductores de la acción dramática lo constituye una dialéctica entre fatalismo y voluntad. En esta obra encontramos dos líneas de personajes paralelas y en relación inversa. Por una parte, Aguilucho y Juana, que se desplazan del fatalismo a la voluntad, por otra Oscar, que va de la afirmación de la voluntad hacia un fatalismo de alguna manera trágico, porque lúcido. Sin embargo, me atrevería a afirmar que, si hacemos una revisión panorámica de la dramaturgia de Acevedo, es posible definir este eje conductor de la progresión dramática de los personajes como un procedimiento permanente en su escritura. Según esto, los personajes pasarían de ser tipos sociales o incluso personajes melodramáticos unidimensionales y estáticos, a representantes de posiciones respecto del eje dialéctico, representantes de cosmovisiones o de intereses en contraposición.

En La canción rota, Salvador, tal como Hurtado lo señala, encarna una cosmovisión socialista revolucionaria, es decir, una concepción dinámica de la historia humana, frente a una forma inercial de la historicidad representada por las costumbres campesinas (171). Sin embargo, Salvador también termina por desplazarse hacia el polo de una fatalidad histórica, completamente 
autoconsciente, que es la conciencia revolucionaria. Los personajes como ideologías históricas, ya no como sujetos individuales. Estamos algo más cerca de eso que Brecht llamó gestus social.

\section{B) IRREDENTOS EN EL LÍMITE DEL DRAMA SOCIAL Y EL TEATRO POLÍTICO}

No han sido pocos los que han subrayado la presencia de elementos de las vanguardias en la escritura de Acevedo. Hurtado (1997) afirma que él impulsa en Chile el teatro moderno que excede la representación realista, y que "junto con Huidobro, Acevedo remece creativamente, desde la dramaturgia, el lenguaje teatral chileno" (190). Pero es quizá Sergio Pereira Poza (2003) quien sea el defensor más categórico de esta hipótesis. En uno de los pocos estudios sistemáticos que se han escrito sobre la obra de este dramaturgo, Pereira Poza señala que lo que caracteriza el trabajo de Acevedo y que habría determinado su relación conflictiva con el medio teatral de su tiempo es que representaría un pensamiento estético alternativo:

Este punto de vista diferente tiene que ver con los materiales que incorpora a sus composiciones, los que tienen un origen simbólico y no puramente referencial. La representación del mundo sostenida por significantes que no refieren contenidos de la realidad práctica es la marca característica de la escritura acevediana. Ella envuelve una posición estética distinta al realismo documental que predomina en el discurso literario de la época. La opción antirrealista que resulta de su rechazo a la referencialidad histórica es congruente con su intención de elaborar una verdad artística que sobrepase los convencionalismos en boga y fuerce al lector a mirar críticamente lo que siempre se le ha presentado como a auténtica verdad (66-7).

A pesar de que el estudio de Pereira no logre siempre poner de manifiesto esta novedad en los textos estudiados, importa cómo la fuerza de esta declaración establece una hoja de ruta para analizar su obra. En el caso de Irredentos, la obra sobre la que quisiera detenerme, podemos apreciar varios de los puntos anteriormente consignados.

Escrita y estrenada en 1918, Irredentos trata sobre la lucha de los trabajadores por condiciones básicas de trabajo, reivindicando el derecho a la huelga como medio para enfrentar el poder de los patrones. Representada insistentemente cada $1^{\circ}$ de mayo por más de 20 años en sedes sindicales y teatros periféricos, con esta obra Acevedo Hernández se adelanta en algunos 
años al surgimiento del “Teatro Político” de Piscator del que posteriormente se declarará deudor.

La obra se ambienta en la ciudad de Valparaíso, en tres espacios diversos, uno por cada acto. El líder de los sindicalistas es Fernando Vial, quien desea conseguir estas mejoras laborales y se enfrenta a un grupo de industriales encabezados por Antonio Abad. Ante la negativa de estos últimos, los trabajadores deciden ir a la huelga. Sin embargo, Abad ha comprado al secretario del sindicato, “el compañero Leal”, para que arme una confabulación contra Vial para indisponerlo ante la asamblea de sus pares y así obligarlos a deponer esta acción, pues los industriales saben, por Leal, que el sindicato no tiene los fondos suficientes para mantenerla. Al final, la asamblea de trabajadores termina por expulsar a Vial del sindicato, acusando a su hermana Julia de pasarles información a los patrones, basados en el hecho de que ella acepta préstamos del más humanitario de éstos, don Augusto Harwey, para iniciar un negocio de costura de pieles. El primer acto se desarrolla en la oficina de Antonio Abad, que es al mismo tiempo su casa, la que se encuentra contigua a la población obrera. En el inicio se exponen las posiciones de los industriales y podemos apreciar una diferencia de criterio entre don Antonio, don José Colly (pretendiente de la hija de Abad) y la posición de Augusto, más llana a concederles a los trabajadores lo que solicitan. En ese momento, ingresa Leal y tiene lugar una escena entre él y Abad en la que los vemos conspirar contra la huelga. En la segunda parte de este acto irrumpe en la oficina Fernando Vial, el presidente del sindicato, que viene a entregar el pliego de peticiones y, ante el rechazo, anuncia el paro. El segundo acto transcurre en la casa del obrero Vial, en él vemos cómo su hermana Julia, enferma tísica, ha pasado la noche en vela para terminar un trabajo de costura. Ha transcurrido tiempo desde el acto anterior, nos enteramos de que la sede sindical fue desalojada de modo violento y Vial ha sido herido por la represión policíaca. Los compañeros irrumpen en su casa solicitándole que participe en una asamblea en la que decidirán si proseguir o no con el movimiento, ante la situación de no tener el sindicato medios económicos para mantenerla. El tercer acto sucede en la sede misma, un galpón atiborrado de obreros que exigen la cabeza de aquel que los habría traicionado, que es realmente Leal, pero éste astutamente ha logrado poner a los concurrentes en contra de Vial, a quien terminan por expulsar, concluyendo la obra de una mala manera para los trabajadores, quienes renuncian a la huelga perdiendo todo lo que solicitaban y, además, a su principal líder. 
Es muy probable que el origen de la trama sea autobiográfico y esté relacionado con el movimiento de los estibadores que tuvo lugar en Valparaíso en 1903, que terminó de forma sangrienta y en la que Acevedo tuvo una presencia activa $^{8}$. Al año siguiente participó en la huelga de los trabajadores ferroviarios de Caleta Abarca y en 1905 en la llamada "Huelga de la carne", en Santiago (Rodríguez 1963: 14). A través de estos tres movimientos, el joven Acevedo no solo conocerá el rostro de la otra pobreza, aquella asociada a las grandes ciudades, también conocerá la violencia a la que es posible llegar en la lucha por los derechos laborales. Es precisamente este asunto uno de los estratos temáticos sumergidos de Irredentos. Aunque el título sugiere un afán redentorista y la trama la gatille la confabulación y traición de Leal, en el fondo, de lo que hablan los sucesos de esta obra es de la inevitabilidad de esta violencia producto de la cerrazón de aquellos que detentan el poder y de aquellos que en la desesperación de la lucha son capaces de no ver lo que ocurre en la realidad. La intimidación de los patrones que amenazan con despidos masivos y con la policía si no bajan el pliego de peticiones, y los trabajadores responden con la amenaza de la huelga general (Irredentos: 26); los golpes que sufre Vial mismo cuando los policías reprimen a los manifestantes a sablazos y balas, el maltrato, en fin, cuando la asamblea expulsa a Vial convencida por Leal de que es aquél el traidor. El motivo de la violencia que, sin embargo, no es extraño a este tipo de tipo de dramaturgia social -ya la vimos en la obra de Hauptmann, la veremos en plenitud en el prodigioso desenlace de La canción rota- encuentra, tal vez, un privilegiado lugar de resonancia en la obra del pensador francés George Sorel titulada: Reflexiones sobre la violencia, publicada por primera vez en $1906^{9}$. Libro que tuvo un impacto en la esfera del anarcosindicalismo y que, contrariamente a los deseos de su autor, fue referencia ineludible de los movimientos fascistas de principio del siglo $\mathrm{XX}^{10}$. Sorel, a quien se considera como el padre del

8 En esta huelga, como me lo ha hecho notar el investigador José Miguel Neira, la figura del almirante Fernández Vial será capital, como mediador. Tal vez el nombre del protagonista de Irredentos, Vial, recuerde a este almirante. Recordemos además que Fernández Vial estuvo fuertemente relacionado con el mundo de los ferroviarios con el que también se relacionó Acevedo.

9 En Chile fue prontamente traducida por la editorial Ercilla en 1932. La edición que citamos es la de Alianza del 2005.

10 Sobre las relaciones entre el teatro de la época y las ideas ácratas véase el interesante ensayo de Sergio Grez Tosso (2011). Pero también el libro de Pereira Poza (2004) 
"sindicalismo revolucionario", afirma en su libro que el mito sobre el cual se ha levantado el socialismo es el de la huelga general:

Cada vez que trata uno de darse cuenta cabal de las ideas que están relacionadas con la violencia proletaria, se ve uno encaminado a referirse a la noción de huelga general [...]

Sabemos que la huelga general es efectivamente (...) el mito en el cual el socialismo entero está encerrado; es decir, una organización de imágenes capaces de evocar de manera instintiva todos los sentimientos que corresponden a las diversas manifestaciones de la guerra entablada por el socialismo contra la sociedad moderna. Las huelgas han engendrado en el proletariado los más nobles sentimientos, los más hondos y los que más mueven; la huelga general los agrupa a todos en un conjunto $y$, al relacionarlos, a cada uno de ellos le confiere su máxima intensidad, (...) Así obtenemos esa intuición del socialismo que el lenguaje no podía expresar de modo perfectamente claro [...] Hay que juzgar los mitos como medios de actuar sobre el presente (Sorel 174, 180).

La vinculación entre mito y violencia revolucionaria es aquí lo capital. En el pensamiento soreliano este mito es tanto una forma de explicar la evolución de la historia, entendiendo por historia el acontecer de los momentos catastróficos, como un instrumento de esos cambios sociales radicales que vienen a transformar para siempre un devenir histórico: una fuerza generadora de la historia.

En el segundo sentido, que es el que nos interesa para el presente análisis, el mito es un activador, una suerte de movilizador de los procesos sociales, pero no en un sentido meramente instrumental, al contrario de una utopía no propone un programa futuro ni señala un proyecto determinado, pues mientras la utopía pertenece a la esfera de la inteligencia, éste convoca aquellas fuerzas más elementales e intuitivas de los seres humanos que no aluden a nuestra dimensión racional, sino a aquello que se halla más allá de la razón, aquello que apela a esa dimensión sublime de la historia y de la vida y en ese sentido puede reunir a la masa en vistas de la acción. El mito no requiere ser consistente con la realidad, no es susceptible a crítica alguna, ni requiere ser verificado. Ingresa en el orden de la acción y no en el de la verdad, incita al hombre a actuar. Su poder entonces se encuentra en su capacidad de evocar y esto lo consigue porque, para Sorel, funciona como una imagen (176) que no persigue explicar una realidad, ni siquiera adelantar un porvenir, sino 
generar un efecto en el presente, ser un medio por el cual sea posible influir sobre el presente (180).

Cuando Sorel afirma que el mito es una fuerza generadora de la historia no debemos olvidar que su concepción de la historia está asociada a lo catastrófico; convoca, entonces, en la medida en que es la imagen de un desastre terrible. Anuncia una transformación del mundo. Pero no da a saber ni cuándo sobrevendrá ni cómo será el mundo trastocado por ella. El mito no anticipa calculadamente como la utopía, señala y procura preparar a los hombres para esta catástrofe. Es bajo estas circunstancias que es capaz de reunir a un pueblo en vistas de la acción. En ese sentido reúne a una comunidad en virtud de un deseo común: la trasformación de la realidad, entendiendo que lo que precede a una transformación es siempre una calamidad por venir. La promesa de ésta sería, en fin, la esencia de esta comunidad en el mito de Sorel. A través de ella ingresa la violencia como el asunto gravitante de este estar-en-común. Por ello, a lo largo de sus Reflexiones Sorel se empeña en demostrar que el uso de ésta con fines revolucionarios no es solo inevitable, sino además legítimo; en efecto, para él cabe llamar así no a cualquier acto de "fuerza", sino aquellos que apuntan a la rebelión. Es la violencia revolucionaria la que queda justificada cuando ésta se ejerce con vistas a la destrucción del Estado.

No se trata de abogar por que la obra de Acevedo sea tributaria de este pensamiento; sin duda, sí lo fue una parte del anarcosindicalismo que emergió en esa época. Lo interesante de esta referencia, es que nos permite develar un pliegue en el binomio huelga-violencia que se estaría jugando al interior del drama de Acevedo. Sin duda la huelga es reivindicada en el texto como una legítima arma de lucha de los trabajadores, pero al mismo tiempo ella es de algún modo espectralizada, es decir, es convertida en el fantasma de una catástrofe por venir. Continuamente aludida por unos y otros, es al mismo tiempo la última moneda de cambio, la amenaza que queda ante la negativa de los industriales de aceptar el pliego de peticiones:

VIAL: Perfectamente. Nos aumentan un diez por ciento que nada remedia, nos harán trabajar en los mismos talleres insalubres, no se preocupan del riesgo obrero, ni de nada. Tenemos la justicia, pero como hoy hasta la justicia se prostituye, apelaremos a la fuerza. Sabemos sufrir, sabemos luchar y es posible que aprendamos a vengarnos. A la indiferencia opondremos la indiferencia; a la fuerza nuestra fuerza... jiremos a la lucha y veremos quién vence a quién! (Pausa.) 
En nombre de nuestros compañeros y ante el rechazo cerrado de nuestras condiciones: ¡declaramos la huelga indefinida! (26)

Es también el fantasma de la derrota que recorre la asamblea sindical como punto de inflexión fatal que condenará a los trabajadores a un estado de subordinación perpetuo:

ARTURO. ¡Justo! ¡Nos han vencido! Nos veremos obligados a trabajar en la forma que ellos quieran, so pena de morirnos de hambre; los pobres somos más refatales...

LEAL: Las huelgas son casi siempre contraproducentes. (60)

En este sentido, Irredentos plantea una crítica al mito de la huelga general, no en el sentido de estar en contra de algo; crítica significa que Acevedo instala la contradicción al interior del binomio al mostrar esta condición espectral que eventualmente puede adquirir el mito paralizando toda acción transformadora. El fantasma del mito es inmovilizador, en la misma medida en que la violencia le es concomitante. Esa pareciera ser la tesis que el personaje de Fernando Vial, de forma algo mesiánica, quisiera enseñarnos, y para ello recurre a la imagen cultural de la redención cristiana. No es que Acevedo defienda una posición religiosa, en un sentido estricto, si asumimos la tesis de la literatura menor, lo que tenemos aquí es un descalce estratégico, una metáfora que desea abrir un brecha que nos percate sobre los peligros de este fantasma que se cierne sobre la comunidad de los trabajadores. El tono mesiánico puede ser interpretado de muchas maneras, entre ellas cabe entenderlo como un recurso retórico-sentimental propio del melodrama de la época más que un objetivo del discurso de este autor. De hecho, en obras posteriores, en La canción rota sin ir más lejos o en Joaquín Murieta (1933), la violencia sigue siendo un tema medular: el fondo sobre el que los personajes actúan y el impulsor del movimiento dramático pero en un tono más trágico que mesiánico. En Cardo negro (1927), la violencia es la moneda de cambio del pobre contra el explotador, su uso es racionalmente justificado, sin alardes retóricos, más con una cierta frialdad. La misma forma en que se exponen las discusiones que tienen lugar en Los caminos de dios (1937), entre las posturas del cura reformista y las del rico hacendado, la violencia, sea lo que define la acción del explotador, sea un posible medio de subversión, aparece como el subtexto de toda confrontación. 
Es posible sostener que en Irredentos la violencia es entendida además como una posibilidad política, no es el último recurso (cf. La canción rota), sino un medio posible del poder, de ahí que en este caso podamos pensar que Acevedo plantea una suerte de crítica de la violencia al instalar la contradicción que conlleva su uso, cuestionando, a su vez, el mito soreliano de la huelga general. Es elocuente este diálogo entre el obrero Alfredo, Julia y el buen industrial Augusto:

Don Augusto: (Sombríamente.) Los industriales supimos que ustedes no poseían fondos, que había un feroz antagonismo entre los dirigentes, que el egoísmo todo lo corroía, que ustedes eran viciosos, y tan poco hábiles, que ni siquiera supieron elegir el momento de levantarse. Aunque esta huelga durara tres meses, los industriales no perderíamos: Hay muchas existencias.

Alfredo: Es que nosotros conocemos medios de hacerlos perder.

JuLiA: La violencia, la acción directa, no... no es un buen medio. Detrás de ella está la cárcel sombríamente horrible, el desprecio, el hambre incisiva, la deshonra íntima. ¡No, la acción directa, no!

Don Augusto: Podrías declarar el "sabotaje” pero qué ganaríais con destruir maquinaria, con incendiar los locales, nada más que miseria, porque no tendríais dónde trabajar. En cambio haríais la fortuna de vuestros enemigos: Las fábricas tienen fuertes seguros. ¿Veis la desigualdad? La lucha es imposible, por lo menos en esta circunstancia.

AlFREDO: ¿¿De modo, señor que nuestro porvenir está determinado?

Don Augusto: Perdéis. Y aunque ganarais, ¿en cuánto tiempo llegaréis al equilibrio económico? Es decir, a recuperar lo que perdéis con el paro; la miseria fisiológica que os asola. El desaliento que os deprime, la desgracia que os estruja. Comprendo que vosotros tenéis derecho a vivir, a gozar de la vida; pero no veo la próxima solución. (Pausa).

AlFREDO: Resistiremos cuanto podamos; somos hombres y los hombres mueren en sus puestos. Deme ese libro, Julia.

Julia: Aquí lo tiene.

Alfredo: Gracias.

JULIA: Yo lo acompañaré. (55-56)

En otras palabras no se da por hecho la violencia como medio, es un asunto a discutir. En eso coincide Irredentos con Los caminos de dios, ambas definidas por Acevedo como "teatro político". A través de este descalce crítico, entramos en una dimensión algo más compleja de lo que a un nivel ostensible nos mostraría el texto, pues al instalar la contradicción, lo que hace es objetivar 
la trama como tal, exponerla como un recurso para algo otro que la mera representación teatral ${ }^{11}$. Una trama que expone su propia autocrítica. Por cierto, no al punto de autocomprenderse como recurso aún, pero lo suficiente como para poner en crisis las formas de representación del naturalismo. Sin alterar radicalmente el estilo, a través de un conjunto de recursos, Acevedo logra este desajuste momentáneo de la convención, pero no por un afán formal, sino por la necesidad de plantear la contradicción en la discusión sobre los medios de lucha del sindicato y en este aspecto se asemeja a la reforma de Hauptmann. Esto último queda en evidencia en el portentoso tercer acto. En él, Acevedo pone en escena nada menos que una asamblea sindical, evidenciando, por una parte, la fragilidad y mezquindad de un movimiento, pero también el poder latente de esas voces que exigen el cumplimiento de los acuerdos, el poder constituyente de una clase que aunque no ha alcanzado una madurez (o plena autoconciencia de clase) se encuentra en el camino de aquello. El mismo año 1918, Armando Moock estrena en Antofagasta su único drama social, Los perros. La trama también se enfoca en un grupo de trabajadores, que viven hacinados en un conventillo de Santiago. El retrato de la pobreza, la enfermedad y los vicios es lo clásico del melodrama naturalista. Lo que tienen en común ambos dramas es el fondo sobre el que se desarrolla la línea argumental: la decisión de un sindicato de ir a una huelga, lo que tendrá lamentables y sangrientas consecuencias. Tal vez lo más elocuente de la obra de Moock sea la tematización de la represión policíaca, cuestión que sabemos fue y sigue siendo muy real. Sin embargo, a diferencia de la obra de Acevedo, la violencia es mostrada unilateralmente, aquí los trabajadores aparecen como simples víctimas de la omnipotencia de los poderosos, lo que se corresponde plenamente con la lógica de un melodrama antes que con la de un drama social. Asimismo, todo el desarrollo del conflicto sucede espacialmente en el interior del cuarto de un conventillo donde viven Modesta, su hija Hortensia y su cuñada Claudina, junto con Máximo y sus dos hijos pequeños y Ciriaco, el hermano de mala vida. La calle, el espacio público, es decir, los espacios donde tienen lugar las decisiones, son solo mencionados por los hombres (varones) que entran y salen de la escena. La casa aparece como el refugio donde los personajes encuentran consuelo de ese amenazante afuera que es,

11 Algunos hablarían aquí de función didáctica; es posible si definimos que didáctico es diferente a pedagógico y que lo didáctico implica desde ya la presencia de un tono épico y distanciado que rompe con la inmanencia de la fábula dramática burguesa. 
en definitiva, el devenir de la historia. Los sucesos de la huelga se convierten así en una suerte de fantasma que acecha la interiorizada seguridad de ese hogar. Modesta -la madre- constantemente reclama a Esteban (pretendiente de Hortensia) y luego a Ciriaco, que no le vengan a sublevar a los niños (7 y 22). La interioridad de la escena es, de algún modo, metáfora descolorida de una subjetividad burguesa que ha devenido alienada, pues, si en el drama burgués el salón es imagen del poder del dueño de casa, aquí el cuarto de conventillo aparece como una endeble réplica, en la que estas mujeres no son dueñas de su destino ni aspiran a ello, son víctimas de su circunstancia. Al final entendemos que lo verdaderamente importante y peligroso sucede afuera, viene desde la calle: los obreros se refugian en el hogar, el hogar es profanado, evidenciando no tan solo la violencia policíaca (cosa que es sin duda real históricamente), también el cumplimiento del sino de esta clase: su derrota. Por eso mismo el diálogo interpersonal no traduce las decisiones de los personajes, tienden a ser comentarios de la situación y lamentaciones sobre su vida, tienden a la conversación antes que al intercambio dramático. Todo lo que ocurre en la obra tiene ese mismo rasgo de sofocante fatalidad: la muerte del hijo de Máximo, el cambio de Ciriaco de vividor a delincuente, la muerte de Esteban, el posible salvador. De hecho, los parlamentos de mayor fuerza social que pronuncia Esteban cuando enfrenta a las clientes ricas de su amada Hortensia que se dedica a la costura o en el momento de informar que los trabajadores han elegido ir a huelga son de un tono autoflagelante, más que iluminador. La utilización de un imaginario relacionado con los desperdicios y la infaltable y patética alusión al perro como imagen del pobre, diluyen todo su potencial crítico por un efecto sentimental. A manera de ejemplo, dos textos:

EstebAN: Eso es lo que tenemos que pedir. No que nos quiten el hambre que sentiremos mañana o pasado, sino que nos den medios para levantarnos del bajo nivel... (22)

Es evidente el dejo asistencialista, no hay indicación alguna a las causas de esta condición, muy lejos de un discurso anarquista o socialista como el que pretende encarnar Esteban. Más adelante dice:

EstebAN: [...] Sí compañeros nosotros somos los perros, los que hociquean y viven de la inmundicia, los que hace siglos nos estamos alimentando de "eso", pero acordémonos que lo que forma ese montón es lo que fertiliza la tierra, lo que la fecundiza y la renueva; es el abono del 
que nosotros nos hemos alimentado, de esos malos humores hemos sacado la fuerza; [...] muchos pobres perros mueren, perros como tú, Cheuto, han sido víctimas del contagio de ese cieno social [...] pero los que quedamos, los que hemos logrado salvar, esos somos fuertes y rudos para la lucha". (23)

Es una imagen al menos ambigua, pues tiende a naturalizar una situación despojándola de su historicidad, como si no tuviese causas y responsables objetivos. Es más un discurso consolatorio que una arenga política o que llame a la toma de conciencia o a la acción; los muertos nos darán la fuerza para la lucha, parece decirnos Esteban, pero no se dice contra qué o quiénes.

Contrariamente a esta visión fatalista, en Irredentos apreciamos algo semejante a lo que ocurre en Almas perdidas, una oposición entre fatalidadvoluntad que constituye una crítica de la fatalidad.

Esto es posible apreciarlo en los personajes que representan, antes que personalidades, puntos de vista, intereses que Acevedo se preocupa de construir dialécticamente. La pobreza de origen de Antonio Abad contrasta con la vehemencia o el énfasis con que defiende sus intereses de industrial. Pero no es que don Antonio esté en un conflicto interior, lo que Acevedo muestra es la contradicción en sus posiciones, para que el público la juzgue, es decir, construye un personaje con su propia crítica (no autocrítica). La lógica de clase es expuesta en tres grupos bien diferenciados, cada cual con sus intereses: oligarquía tradicional (paternalismo), la clase emergente (nuevos ricos, arribismo) y los trabajadores (entre la conciencia mesiánica y no-conciencia como determinismo). Augusto representa el paternalismo de una oligarquía burguesa e ilustrada de cierta tradición que concuerda con los avances, pero es claro en mantener las distancias entre las clases. Antonio Abad y principalmente José Colly representan el tipo ascendente, de orígenes pobres y que se empeñan en ejercer un papel exageradamente autoritario y clasista, sobreactúan, lo cual se pone en evidencia en el primer acto. Colly es el sujeto del capitalismo pragmático, el único interés es su propio bienestar, en cambio en Antonio hay una defensa corporativa del gremio industrial. Finalmente los trabajadores divididos entre dos pulsiones: una mesiánica (Fernando Vial), la otra alienada. Sin embargo, un intersticio lo constituye Alfredo, quien termina por ser el sujeto de la lucidez, mucho más que Vial; Alfredo es como Aguilucho en Almas Perdidas, un personaje secundario que releva la posta del héroe protagónico, pero que permite avanzar del mesianismo a la autoconciencia de clase. 
Llama la atención también el carácter que adoptan algunos diálogos que de intercambios interpersonales devienen argumentaciones con réplicas y contrarréplicas, especialmente la última escena del acto I y las intervenciones de Alfredo. A pesar de que tanto Vial como Alfredo corresponden al personaje propio del melodrama, el tipo social, son también portadores de los intereses de una clase, es decir, de posiciones ideológicas y su función es exponer las condiciones materiales de explotación y desmedro en que se encuentran como trabajadores con reivindicaciones sumamente puntuales:

VIAL. La asamblea de mi gremio, comprendiendo que es inhumano que esta situación continúe, y en vista de no haber sido aceptado nuestro anterior pliego de condiciones, ha acordado, por nuestro intermedio, elevar el presente, que me hago el deber de poner en sus manos.

Don Antonio. ¿y si yo me negara a aceptarlo?

Alfredo. Adoptaríamos otro temperamento.

Vial. No cree la Asamblea que los industriales sean tan injustos, que no tomen en cuenta sus atinadas peticiones. No pedimos ninguna cosa del otro mundo; ganamos menos de lo que consumimos y trabajamos más de lo que podemos y debemos. La vida se hace imposible. Por causa de la carestía no podemos comprar los productos alimenticios más necesarios. ¡No nos alcanzan nuestros enormes jornales!

Don José. Esa petición es una letanía que nos sabemos de memoria. Pero también sabemos que las fortunas se elevan superponiendo centavos y estimamos que los viciosos merecen el castigo de la miseria.

(Los delegados dejan oír un murmullo de protesta.)

VIAL. Calma, compañeros. Este caballero repite una lección aprendida y es maestro en el arte de buscar tres pies al gato. Pero yo lo invito a que me pruebe que soy vicioso y lo desafío a vivir una semana trabajando como yo y con mis medios de subsistencia.

Don José. Es que mi situación es diferente: yo tengo mayor significación en la vida.

ARTURo. Este caballero, tiene dos estómagos y doble estatura de la nuestra; significa más en la vida porque produce menos.

Don Antonio. Pido más compostura: no estamos dispuestos a tolerar insolencias.

VIAL. La primera insolencia ha partido de ustedes. Se han negado a recibir el pliego de condiciones. Este documento representa la voluntad de diez mil operarios que significan en la vida, más que usted don José, porque elaboran la riqueza de un pueblo; porque dominando la maquinaria dan vida al progreso que es el alma de todo. Estos diez 
mil operarios tienen hogar, familias, hijas del amor fatigado que ha florecido junto al hierro de la máquina, bajo el adusto servilismo del mayordomo y la indiferencia del patrón. Esta población tiene hambre, jos lo juro! Y pide apenas lo necesario para seguir vegetando, ya que nunca vivirá. No somos viciosos, señores, nuestro jornal no alcanza para vicios; pues el vicio, lujo refinado, es enfermedad de las aristocracias.

$$
\text { [...] }
$$

Don Augusto. ¿Qué punto es el que más os interesa?

VIAL. Todos son primordiales. Pero hemos marcado con tinta roja las peticiones que estimamos más atendibles: como el aumento de salario, seguro obrero, medios salarios para niños y enfermos, cajas de ahorros, socialización de las fábricas, disminución de horas de trabajo y feriados legales. (22-24)

Sin embargo, la evolución de la trama va invirtiendo este primer foco centrado en el conflicto de la lucha de ricos contra pobres hacia el conflicto de los trabajadores con su propia clase. Aquí cobra importancia el motivo de la traición. Sobre el fondo de un imaginario de inspiración cristiana, la traición es posible entenderla como una alegoría de la derrota, que instala nuevamente la contradicción en el supuesto naturalista de la fatalidad. La obra parece querer indicar que los únicos responsables finalmente es la propia clase obrera, ellos son los protagonistas de su propia derrota y no los patrones. Los trabajadores pasan a ser así personajes activos de la trama y ya no meras víctimas de las circunstancias. En este sentido la traición de "Leal”, tal como la de Judas (o la de Caín en la obra homónima de Acevedo) representa una alegoría de la capacidad de transgredir el destino que ha sido prescrito. Si bien Vial no es el traidor, la marca de Caín recae sobre él y no sobre Leal que finalmente triunfa, porque vencen los patrones. Vial es nuevamente ese Salvador o ese Oscar que como un extranjero viene a decirles a los pobres que la única salida es la conciencia activa de clases, pero será incomprendido y, como Caín, cargará con la marca, no de una culpa, sino de la irreversible finitud de la decisión que da lugar a la historia.

Pero sin duda el recurso más sobresaliente y transgresor es la forma cómo Acevedo comprende la espacialidad como un personaje más, es decir como un componente y activador de la acción dramática. Irredentos está estructurada en tres actos que son definidos por tres espacios diferentes y en contrastaciones mutuas. El primer acto sucede dentro de las elegantes oficinas de don Antonio Abad, el segundo en la pobre casa de los Vial. El tercero el más notable, a mi modo de ver, es la sede-galpón del sindicato de 
trabajadores donde se lleva a cabo una impresionante asamblea. Es decir, desde los ámbitos íntimos propios del teatro burgués, al naturalista propio del melodrama social, para finalizar en el espacio público del galpón del sindicato. Es notable además si lo comparamos con Los Perros de Moock, en que la acción dramática transcurre siempre en el mismo entorno cerrado de la casa del pobre y las virtuales escenas donde deciden irse a la huelga o abogar por la vía violenta aparecen solo como comentarios: no tienen realidad dramática. Acevedo, en cambio, con este tercer acto le da realidad dramática a las acciones que identifican a la clase trabajadora, con lo peligroso que ello significa, pues evidenciarla dramáticamente significa mostrarla en sus contradicciones, sus virtudes y bajezas. Los tres espacios constituyen, así, una suerte de dialéctica del territorio. El primero: la casa-oficina de Antonio Abad representa el lugar afirmativo del poder, la alienación de lo público por la clase dominante. Tiene sentido, pues, que sea trasgredido discursivamente por los sindicalistas. El segundo es el ámbito de la intimidad como reflejo antitético del anterior y representa el imaginario melodramático, es decir, el territorio alienado del pueblo. Finalmente la resolución dialéctica en la zona propiamente política/pública, el lugar de la decisión soberana de la asamblea. Hay pues una crítica al modo de concebir el espacio del naturalismo y erige un nueva concepción que abandona lo atmosférico por la materialidad de un territorio en el que tiene lugar la exposición de las condiciones de estos trabajadores, mostrándolos como sujetos, equivocados o no, de sus decisiones.

Esta materialidad podría concebirse también como paisaje: el conventillo, la ciudad obrera, son paisajes que determinan a sus habitantes y que se construyen también sonoramente. En el primer acto es notable la permanente relación del adentro y el afuera, la que hace notar Isabel, quien contrapone la música que ella interpreta al piano con la música de los pobres, el sonido del organillero y de los niños que juegan. En el segundo acto, el repiqueteo de la máquina de coser de Julia como un zumbido maquinal en contrapunto de la musicalidad de la casa de Abad. El tercer acto es la bulla del espacio público, un grupo humano que hierve, que grita y se enrostra sus mutuos comportamientos.

En síntesis ${ }^{12}$, sin duda Irredentos es un (melo)drama social que asume las características genéricas de toda obra de esta clase, pero podemos encontrar

12 Queda, sin embargo, pendiente pensar una tensión que es posible apreciar en la obra de Acevedo entre dos polos posibles de lectura: entre lo político y lo teológico, entre una pragmática del cambio social y lo mesiánico. 
en él interrupciones momentáneas de la convención que lo acercan a un embrionario tipo de teatro o drama político.

\section{BIBLIOGRAFÍA}

Acevedo Hernández, Antonio. Irredentos. Santiago: Soc. Imprenta y Litografía Universo, 1918. La canción rota. Santiago: Editorial Nascimento, 1933. Almas perdidas. Santiago: Mundo Teatral n²0, 1919. Los caminos de dios. Inédito. Copia mecanografiada. Cardo negro. Santiago: Editorial Nascimento, 1933. Caín. Santiago: Editorial Nascimento, 1927. Joaquín Murieta. Santiago, Excelsor I, 1, agosto 1936.

“Consideraciones sobre el teatro chileno”. Atenea 96, Año X. Tomo XXIII, abril 1933: 309-319.

Agamben, Giorgio. "Qué es lo contemporáneo”, trad. Cristina Sardoy. El Clarín. Buenos Aires, 21 de marzo 2009.

Barría Jara, Mauricio. “Alegoría y menoridad. Dos estrategias filosóficas para la interpretación de textos dramatúrgicos contemporáneos y no tantos”, Gestos 60. Irvine, California (en prensa).

Benjamin Walter. "El autor como productor”, en Benjamin Walter, Tentativas sobre Brecht. Madrid: Taurus, 1998.

Büchner, Georg. La muerte de Danton; Leonce y Lena; Woyzeck. Buenos Aires: Ediciones Nueva Visión, 1960.

De Vicente, César, La escena constituyente. Teoría y práctica del teatro político. Madrid: Centro de Documentación Crítica, 2013.

Deleuze Gilles y Félix Guattari. Kafka, por una literatura menor. México: Era, 1978.

Durán, Julio. Panorama del teatro chileno. Santiago: Ed. Pacífico, 1959.

Fernández Insuela, Antonio. "Sobre el nacimiento del teatro social español y su contexto". Monteagudo, $3^{\circ}$ época, $n^{\circ} 2,1997:$ 13-28.

Gadamer George. Verdad y Método. Salamanca: Ed. Sígueme, 1999.

Grez Toso, Sergio. “¿Teatro ácrata o teatro obrero? Chile, 1895-1927”. Estudios Avanzados 15 (Jun. 2011): 9-29.

Hauptmann, Gerhard. Los tejedores. Buenos Aires: Losada, 1958.

Hurtado, M. de la Luz. Teatro chileno y modernidad: identidad y crisis social. Irvine, California: Ediciones GESTOS, 1997.

Kleist, Heinrich von. Pentesilea. Barcelona: Labor, 1973.

Moock, Armando. Los perros. Buenos Aires: La Escena Teatral, n¹93, marzo 1922. 
Pereira Poza, Sergio. Antología crítica de la dramaturgia anarquista en Chile Santiago: Universidad de Santiago de Chile, 2005.

Dramaturgia social de Antonio Acevedo Hernández. Santiago: Universidad de Santiago de Chile, 2003.

Rodríguez, Orlando B. “El teatro chileno entre 1900 y 1940”, en Piga, Domingo T. y Orlando

B. Rodríguez, Teatro chileno del siglo veinte. Santiago: Universidad de Chile, 1964.

Piscator, Erwin. El teatro político. Hondarribia: Hiru, 2001.

Pradenas, Luis. Teatro en Chile: huellas y trayectorias. Siglos XVI-XX. Santiago: LOM, 2006.

Rodriguez, Orlando. Prólogo a El Triángulo tiene cuatro lados. Santiago: Imprenta y Litografía Bolívar, 1963.

Teatro Chileno (Su dimensión social). Santiago: Quimantú, 1973.

Sorel, Georges. Reflexiones sobre la violencia. Madrid: Alianza Editorial, 2005.

Szondi, Peter. Teoría del drama moderno: 1880-1950; tentativa sobre lo trágico. Barcelona: Ediciones Destino, 1994.

Williams, Raymond. El teatro de Ibsen a Brecht. Barcelona: Ediciones Península, 1975. 